\title{
Avaliação de fenótipo: a participação do assistente social
}

Phenotype evaluation: the role of social workers

Thais Felipe Silva dos Santos*

Maria Beatriz da Rocha Alarcón**

Edna Fernandes da Rocha***

\begin{abstract}
Resumo - O objetivo deste artigo é fornecer elementos para o debate sobre a participação do/a assistente social na política de ações afirmativas na comissão de avaliação de fenótipo de concursos públicos. Para isso: (a) delineamos a forma de inserção do/a assistente social na comissão de avaliação de fenótipo no certame do Tribunal de Justiça de São Paulo ocorrido em 2017; (b) refletimos sobre a formação do/a assistente social com base no materialismo histórico-dialético e os elementos teóricos, éticos e políticos que propiciam ao/à profissional atuar no combate ao racismo; (c) partilhamos o relato de experiência de avaliação aos/às candidatos/as na comissão de fenótipo e o rebatimento do racismo estrutural que marca a vida da população negra; e (d) pontuamos algumas proposições que permitem aos/às assistentes sociais refletir e debater sobre a formação profissional do/a assistente social e a atuação na luta antirracista.
\end{abstract}

Palavras-chave: ações afirmativas; Serviço Social; racismo.

Abstract - This article's purpose is to provide arguments for the debate on the participation of social workers in phenotype evaluation committees of affirmative action policies in public tendering. In order to do this, we: (a) outline the insertion of social workers in the phenotype evaluation committee for the tendering of civil servant positions in the São Paulo Court of Justice in 2017; (b) reflect on the formation of social workers based on historical-dialectical materialism and the theoretical, ethical, and political elements that enable these professionals to work in the fight against racism; (c) share the experiences

\footnotetext{
* Assistente social. Mestranda em Serviço Social pela Pontifícia Universidade Católica de São Paulo na modalidade de cotas raciais com fomento da Coordenação de Aperfeiçoamento de Pessoal em Nível Superior. Assistente Social no Tribunal de Justiça de São Paulo. E-mail: thaislipe@gmail.com. ORCID: https://orcid.org/0000-0001-7207-578X. ** Assistente social. Mestre em Serviço Social pela Pontifícia Universidade Católica de São Paulo. Assistente Social no Tribunal de Justiça de São Paulo. E-mail: biarocha54@hotmail.com. ORCID: https://orcid.org/0000-0002-65130020 .

*** Assistente social. Doutora e Mestre em Serviço Social pela Pontifícia Universidade Católica de São Paulo. Assistente Social no Tribunal de Justiça de São Paulo. E-mail: ednafr.rocha@gmail.com. ORCID: https://orcid.org/0000-00033017-563X.
} 


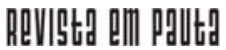

\} AVALIAÇÃO DE FENÓTIPO - SANTOS, T. F. S.; ALARCÓN, M. B. R.; ROCHA, E. F. \}

DOI: $10.12957 /$ REP.2020.51985

of candidate evaluation from members of the phenotype evaluation committee and the rejection of the structural racism that marks the life of the black population; and (d) outline some proposals that could allow social workers to reflect and debate on the professional training of the field and anti-racism action.

Keywords: affirmative action; Social Work; racism.

\section{Introdução}

É preciso deixar mais claro o que nós sabemos, assumir que sabemos, pois o saber que o Serviço Social domina vem de todos os seus conhecimentos teóricometodológicos, mas vem também do conhecimento da realidade onde atuamos. (MARTINELLI, 2006, p. 15).

O objetivo deste artigo é fomentar o debate sobre a participação do/a assistente social na comissão de avaliação de fenótipo em concursos públicos, uma vez que esses/as profissionais foram convocados/as para compor a Comissão no Certame para o provimento de cargos vagos de assistente social judiciário/a, psicólogo/a judiciário/a e escreventes, ocorrido no ano de 2017.

O Tribunal de Justiça de São Paulo (TJSP, 2015) editou a Resolução n. $719 / 2015$, que regulamenta a reserva, aos/às negros/as, de 20\% das vagas oferecidas nos concursos públicos para provimento de cargos efetivos e na magistratura, em atendimento à Lei n. 12.990, de 9 de junho de 2014 (BRASIL, 2014); ao Estatuto da Igualdade Racial, Lei n. 12.288, de 20 de julho de 2010 (BRASIL, 2010); ADPF 186/Distrito Federal do Supremo Tribunal Federal (BRASIL, 2009); ao Primeiro Censo do Poder Judiciário, realizado pelo Conselho Nacional de Justiça (CNJ, 2014); às deliberações do plenário do CNJ (2012) nos autos do Pedido de Providências n. 000224846.2012.2.00.0000 e do processo da Comissão n. 000694088.2012.2.00.0000, na 210 a Sessão Ordinária, realizada em 9 de junho de 2015 (CNJ, 2015b); e à Resolução CNJ n. 203/2015. Em seu Art. 5, a mencionada resolução versa que:

o candidato que optar concorrer às vagas reservadas aos negros ainda que aprovado dentro do número de vagas oferecido à ampla concorrência, deverá participar de entrevista com uma Comissão de Avaliação que emitirá parecer quanto à veracidade da autodeclaração de cor ou raça. (TJSP, 2015, p.3).

Em seu artigo $6^{\circ}, \S 1^{\circ}$, disciplina que "A Comissão de Avaliação será composta por um Juiz, um Médico e um Assistente Social, do quadro do Tribunal de Justiça, que serão designados pelo Presidente da Comissão 


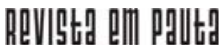

\} AVALIAÇÃO DE FENÓTIPO - SANTOS, T. F. S.; ALARCÓN, M. B. R.; ROCHA, E. F. \}

DOI: $10.12957 / R E P .2020 .51985$

do Concurso" (TJSP, 2015, p.3). Segundo o Conselho Federal de Serviço Social (CFESS, 2016), as políticas afirmativas discriminam de forma inclusiva, uma vez que visam reparar danos e dívidas históricas produzidas e herdadas em desfavor da população negra ante a uma estrutura socioeconômica que produz determinações contraditórias. Entendemos que se trata de uma resposta institucional datada, de combate ao racismo, por meio de ações afirmativas; porém, dizemos datada porque a Resolução do CNJ no 203/ 2015 prevê a reserva de vagas no âmbito do Poder Judiciário para pessoas negras em concursos que se realizarem até 9 de junho de 2024 (CNJ, 2015a). Nesse sentido, citamos Almeida (2018, p. 40), para quem "a mudança da sociedade não se faz apenas com denúncias vazias ou o repúdio moral do racismo: depende, antes de tudo, da tomada de postura e da adoção de práticas antirracistas".

A formação profissional do/a assistente social é generalista, com vistas a possibilitar a apreensão e intervenção nas expressões da questão social que se materializam nos diversos espaços sócio-ocupacionais da prática profissional. Entendemos que o racismo é uma forma de relação social que produz atos concretos e contribui ainda mais com a desigualdade social oriunda da sociedade capitalista. Nesse sentido, lamamoto (2014), ao se debruçar sobre as diretrizes curriculares da Associação Brasileira de Ensino e Pesquisa em Serviço Social (ABPESS - 1996), aponta que essas normas possibilitam um arcabouço teórico-metodológico e ético-político que preveem

viabilizar a capacitação teórico-metodológica e ético política como requisito fundamental para o exercício de atividades técnico-operativas, com vistas à: apreensão crítica dos processos sociais numa perspectiva de totalidade e do movimento histórico da sociedade brasileira; [...], desvelando as possibilidades de ação contidas na realidade; e identificar demandas presentes na sociedade, visando formular respostas profissionais para o enfrentamento da questão social, considerando as novas articulações entre o público e o privado. (IAMAMOTO, 2014, p. 619 - grifos nossos).

A autora também indica que as diretrizes trazem a proposta da

adoção de uma teoria social crítica que possibilite a apreensão da totalidade social em suas dimensões de universalidade, particularidade e singularidade; debate entre tendências teóricas presentes nas ciências humanas e sociais... (IAMAMOTO, 2014, p. 619).

A totalidade, um dos pilares de sustentação metodológica do Serviço Social, conforme indica Souza (2009), permite-nos recorrer às bases necessárias para as "mediações existentes na realidade concreta dos sujeitos" (CFESS, 2016, p. 15) que se inscreveram no concurso por meio da reserva de vagas aos/às negros/as. Por sua vez, a categoria mediação possibilita 


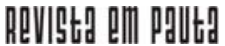

\} AVALIAÇÃO DE FENÓTIPO - SANTOS, T. F. S.; ALARCÓN, M. B. R.; ROCHA, E. F. \}

DOI: $10.12957 /$ REP.2020.51985

ultrapassar a aparência e apreender a essência do fenômeno de avaliação do fenótipo. Essa forma de análise para o Serviço Social advém das Diretrizes Curriculares que determinam a formação profissional (BRASIL, 1999).

Desta feita, a avaliação de fenótipo nos coloca em contato com a realidade dos sujeitos inscritos nessa condição. A permanência, literalmente, face a esses sujeitos, com as bases teórico-metodológicas do Serviço Social, possibilita-nos apreender muito mais do que o tom da pele e os caracteres aparentes; nos permite fazer mediações sócio-históricas que caracterizam a singularidade dos indivíduos com aquele fenótipo. Esse percurso de apreensão da realidade proporciona a saída do nível do aparente para adentrarmos em processos sócio-históricos, os quais conferem reais contribuições para a participação do/a assistente social nas Comissões de Avaliações. Sendo assim, Moraes e Martinelli $(2012$, p. 5) ensinam que

O processo de alcance da essência ocorre mediatizada pela aparência, pelo fenômeno, porém, devemos visualizar os fenômenos sociais como complexos sociais ao invés de fatos isolados, pois esses complexos que são estruturas sócio-históricas, vivas e reais, que compõem o ser social.

De acordo com Douglas (2017), no Brasil, as ações afirmativas são voltadas para quem tem a aparência física (fenótipo), e não o sangue (genótipo). O mesmo autor, em coautoria com Frei David Santos, refere que, se em algum momento a autodeclaração deu conta da inserção de negros/as nos concursos e em vagas de universidade, hoje, percebemos, por meio dos diversos aparatos midiáticos e de processos propostos pelo Ministério Público, que pessoas mal-intencionadas se valem dessa política afirmativa para desrespeitar as cotas (DOUGLAS; SANTOS, 2016). Douglas (2017, p. 4) afirma, ainda, que "deixando que todos a utilizem [as cotas] prejudica a política pública, desmoraliza o instituto e, pior, privilegia os 'malandros' em prejuízo daqueles que efetivamente merecem o benefício".

Nesse sentido, compreendemos que o arcabouço teórico mencionado, pertinente à formação do/a assistente social, tem contribuições a oferecer, por isso o/a profissional é convocado a intervir. Conforme norteado pelo CFESS (2016, p. 15-16),

o fortalecimento das lutas populares no empenho para a eliminação de todas as formas de preconceito, a defesa intransigente dos direitos humanos e o reconhecimento da liberdade como valor ético central devem constituir os princípios que nortearão a defesa das ações afirmativas.

A Resolução n. 719/2015 do TJSP (2015), em consonância com o proposto pelo Ministério do Planejamento, Desenvolvimento e Gestão, em seu art. $6^{\circ}, \S 2^{\circ}$, estabelece que 
A avaliação da Comissão de Avaliação quanto à condição de pessoa preta ou parda considerará os seguintes aspectos:

a) informação prestada no ato de inscrição quanto à condição de pessoa preta ou parda;

b) fenótipo do candidato verificado pessoalmente pelos componentes da Comissão.

A experiência do TJSP demonstrou que, embora tenha privilegiado a autodeclaração, também reafirmou o alcance e a objetividade da política pública ao criar a Comissão de Avaliação. Assim, fortalecer a política pública fomenta o ingresso da população negra no mercado formal de trabalho em cargo efetivo e, consequentemente, diminui a vulnerabilidade social. Além disso, é importante destacar que

[a] ausência histórica de Políticas Sociais que desde a abolição permitiu que os mesmos [negros] permanecessem à margem da sociedade, fato que associado à negação do racismo, dificultou a mobilização dos movimentos sociais na luta contra a desigualdade racial. (CRUZ; SANTOS; SILVA, 2016, p. 13).

Desta forma, entendemos que a criação da Comissão de Avaliação do TJSP contribuiu efetivamente para o combate ao racismo e às fraudes. Koga, Sant'Ana e Martinelli (2018) alertam que a classe trabalhadora mais vulnerável, neste país, sempre teve sexo e cor. Nesse sentido, Motta (2018, p. 73-74) pontua que a classe revolucionária tem uma materialidade, e é imprescindível "entendermos que ela porta um corpo que está situado numa sociedade em que os signos também atuam para estigmatizar e excluir".

Magali da Silva Almeida (apud CRUZ; SANTOS; SILVA, 2016, p. 6) destaca que, ao defender políticas afirmativas, a profissão busca a efetivação de direitos para grupos que têm a marca da discriminação em sua história, e reafirma:

as políticas de igualdade de direitos são uma conquista e se encontram na área de atuação do Serviço Social como forma de mediação dos conflitos raciais que totalizam mais uma expressão da questão social.

O Código de Ética do/a Assistente Social (CFESS, 2012) reconhece a liberdade como valor ético central e as demandas políticas a ela inerentes; propõe a defesa intransigente dos direitos humanos; o empenho na eliminação de todas as formas de preconceito e a não discriminação como princípios éticos fundamentais, que são balizas que revelam a relevância da defesa das ações de políticas afirmativas, conforme preceituado pelo CFESS (2010). Nesse cenário, afirmou Mesquita (2010, p. 8):

É em busca desse horizonte que as Ações Afirmativas devem ser apreendidas pelo conjunto da categoria profissional, pois há uma es- 


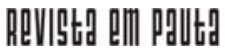

\} AVALIAÇÃO DE FENÓTIPO - SANTOS, T. F. S.; ALARCÓN, M. B. R.; ROCHA, E. F. \}

DOI: $10.12957 /$ REP.2020.51985

treita relação entre os princípios do nosso Código de Ética Profissional, das Diretrizes Curriculares e as lutas anti-racistas nesse país.

Dentre os 11 princípios fundamentais que balizam o projeto e os compromissos ético-políticos, destacamos o apontamento de Paiva e Sales (2012, p. 241 - grifos nossos) acerca do oitavo princípio:

A atenção dedicada às distintas determinações do ser social - etnia, [racial] e gênero - é um dos recortes explicativos e configuradores da identidade e particularidade dos indivíduos sociais. Essa nova inflexão sociopolítica e antropofilosófica assinalada pelo Código de Ética amplia o campo de preocupações e de proposições interventivas para o Serviço Social, oportunizando a contemplação da perspectiva da totalidade.

Esse giro ético-cultural propicia ao assistente social na relação direta com os usuários e grupos, no trabalho com comunidades, na formulação de programas e políticas sociais- valiosos elementos e subsídios que reafirmam a sua qualificação e contribuição profissional legitimado para o trabalho e luta no campo da defesa e ampliação dos direitos e cidadania.

Embora não se trate de uma atribuição privativa, pois o combate ao racismo não é tarefa somente ao/à profissional de Serviço Social, mas uma temática estrutural e por isso diz respeito a diversas áreas do conhecimento, o cenário exposto nos faz pensar que compor a Comissão de Avaliação abrange uma competência do/a assistente social, uma vez que o/a coloca em consonância com os princípios éticos da profissão. Porém, cabe perguntar: será que o/a assistente social no espaço sócio-ocupacional do cotidiano de trabalho não consegue identificar o rebatimento da questão racial sobre as pessoas não brancas?

\section{A atuação do/a assistente social na Comissão de Avaliação}

A proposta de atuação na Comissão de Avaliação de fenótipo para os cargos de assistente social, psicólogo/a e escrevente foi discutida coletivamente entre os membros da presidência da Comissão Examinadora do certame, os componentes da Comissão de Avaliação de Fenótipo e o integrante do Departamento de Recursos Humanos e do Núcleo de Assistentes Sociais e Psicólogos do TJSP. Vale destacar que, entre os componentes, estavam assistentes sociais, médicos e juízes, e a nossa voz não foi hierarquizada.

Também merece destaque que a indicação do Serviço Social para compor a Comissão de Avaliação partiu da então diretora de Recursos Humanos, porque, em sua visão, o/a assistente social teria muito a contribuir nesse processo. Dessa maneira, é surpreendente notar que outras profissões 


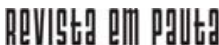

\} AVALIAÇÃO DE FENÓTIPO - SANTOS, T. F. S.; ALARCÓN, M. B. R.; ROCHA, E. F. \}

DOI: $10.12957 /$ REP.2020.51985

tinham a compreensão da importância da atuação do/a assistente social na comissão, enquanto que, em nossa profissão, o racismo era subobservado. Igualmente, na atual gestão do CFESS, a temática racial ganhou força e visibilidade.

Consideramos que a classe trabalhadora precisa ter identificadas suas particularidades. Quem são os sujeitos que compõem essa classe? Quais impactos suas caraterísticas raciais e de sexo trazem para sua condição de classe? Esse sujeito existe com suas singularidades que precisam ser consideradas ao tratarmos sobre a classe e entendemos que, na avaliação de fenótipo, teríamos esse olhar atento para os membros da classe trabalhadora que se declaram como pretos/as ou pardos/as para alcançar um emprego estável por meio de um concurso público.

Apesar dos critérios estabelecidos no edital, que seguiam as indicações do Instituto Brasileiro de Geografia e Estatística (IBGE), também compareceram candidatos/as que não possuíam fenótipo preto ou pardo. Nas avaliações de fenótipo dos candidatos que concorreram às vagas de assistentes sociais e psicólogos/as, deparamo-nos com profissionais que em sua expressiva maioria já haviam passado pelo processo seletivo de cotas raciais quando disputaram vaga no ensino superior. Diante de tal vivência, alguns/algumas candidatos/as apontaram brevemente que passaram por entrevistas, a fim de certificarem seu fenótipo racial, mas as experiências foram distintas quanto à metodologia ora empregada.

Não obstante a qualificação adquirida, muitos/as candidatos/as, inclusive pós-graduados/as ou em processo de especialização, revelaram sua expectativa em ocupar espaço de trabalho público, superando mais uma etapa da discriminação racial vivenciada tanto social como profissionalmente. Nesse contexto, cabe ressaltar que, passados 15 anos da implantação das primeiras e pioneiras experiências de ações afirmativas, registradas na Universidade de Brasília (UnB), apesar de o número de negros/as ter crescido, ainda está longe de alcançar o de brancos/as graduados/as nas universidades. Segundo Brito (2018) ao analisar a política de ação afirmativa, os dados do IBGE (2000) indicavam que enquanto que $22,9 \%$ da população branca conclui a universidade, essa realidade só atinge 9,3\% da população negra.

A Lei de Cotas, como uma política pública, tem como objetivo reparar a situação atual de discriminação que atinge esse grupo. A proposta originária estabelece que, a cada 10 anos, essa política seja avaliada e revisada, o que ocorrerá em 2022, a fim de mensurar as mudanças obtidas e redesenhá-las para atender a atual demanda. Como bem afirmou, em entrevista, a professora da UnB Renísia Filice ${ }^{1}$ - doutora em educação e pósgraduada em estudos étnicos e raciais -, "o sistema de cotas abalou a con-

\footnotetext{
${ }^{1}$ Disponível em http://agenciabrasil.ebc.com.br/geral/noticia/2017-11/negros-enfrentam-mais-dificuldades-quenegros-no-mercado-de-trabalho-diz-mpt. Acesso em 7 fev. 2019.
} 


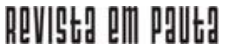

\} AVALIAÇÃO DE FENÓTIPO - SANTOS, T. F. S.; ALARCÓN, M. B. R.; ROCHA, E. F. \}

DOI: $10.12957 /$ REP.2020.51985

juntura, mas não mudou a estrutura", constatação que corrobora nosso entendimento, já apontado, de que o racismo é uma forma de relação social produtora de atos concretos que contribui ainda mais com a desigualdade social oriunda da sociedade capitalista.

Boehm (2017) apresenta dados da Associação Brasileira de Pesquisadores Negros sobre os desafios enfrentados pelos negros no mercado de trabalho e aponta três tipos de discriminação frequentes no ambiente de trabalho: a primeira é a ocupacional, que questiona a capacidade do/a negro/a de desempenhar tarefas mais complexas, mesmo que esse profissional seja capacitado/a para tais funções; a segunda é a discriminação salarial, com o desrespeito à equiparação na remuneração de brancos/as e negros/as, sugerindo que o trabalho feito pelo/a negro/a tem menor valor; a terceira é a discriminação pela imagem, na qual a pele escura e os cabelos crespos são alvo de preconceito e deixam os/as negros/as de fora de diversas oportunidades de trabalho.

$\mathrm{Na}$ avaliação para os/as candidatos/as inscritos/as para o cargo de ensino médio, as expressões da questão social despontaram com aspereza imiscuída com racismo, desigualdade, miséria, inferioridade, moradia em bairros periféricos e toda treva de dissabores oriundos de uma sociedade racista que fez da cor da pele um marco para a exclusão social. A partir disso, surgem contextos e particularidades que dizem da condição social que assola a maior parte da população negra do país. São relações sociais que demonstram as determinações que cercam as vidas das pessoas não brancas, sobretudo com maior intensidade daquelas identificadas em seu fenótipo como pretas e pardas.

$\mathrm{Na}$ interação com os/as candidatos/as, surgiram elementos que indicam as condições de sobrevivência desses sujeitos, com destaque para a condição social. Tratava-se de um concurso local, no entanto, pessoas de diversas partes do país concorreram às vagas oferecidas. Vieram candidatos/ as do interior de São Paulo, Amazonas, Sergipe, Minas Gerais, Paraná, Rio de Janeiro, Espírito Santo, Pernambuco, Santa Catarina, Bahia e Mato Grosso, dentre outros estados. Algumas pessoas pretas e pardas apresentavam-se para avaliação com malas de viagem, vindas diretamente da rodoviária ou do aeroporto.

A falta de perspectiva para o trabalho pode levar o sujeito à migração, e essa mobilidade denuncia a complexa realidade de seu local de moradia. Gois (2014, p. 24) refere que

Essa experiência do deslocamento do indivíduo do espaço sociocultural onde nasceu e se socializou para um que lhe é desconhecido e do qual, por vezes, não tem nenhuma referência, impõe um processo de reinserção social dificílimo de ser realizado com autonomia. Em algumas circunstâncias, exige, inclusive, significativas alterações no padrão de sociabilidade, especialmente quando se trata de migrações do espaço rural para o urbano ou de cidades de pequeno 


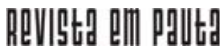

\} AVALIAÇÃO DE FENÓTIPO - SANTOS, T. F. S.; ALARCÓN, M. B. R.; ROCHA, E. F. \}

DOI: $10.12957 / R E P .2020 .51985$

porte para metrópoles, o que demanda suporte para sua realização por meio de políticas públicas de proteção social.

As dificuldades de inserção no mundo do trabalho e a consequente migração mencionada trazem diversas sequelas da questão social, como rompimentos de vínculos familiares, de pertencimento e identidade, assim como o enfrentamento de ser diferente num lugar que muitas vezes emerge como hostil, dentre outras violências resultantes do desenraizamento em busca de trabalho. Segundo Martinelli (2013, p. 146), identidade como categoria ético-política construída no "fértil terreno da diferença, no interior de relações sociais antagônicas".

Além disso, ao realizar o breve acolhimento do/a candidato/a, observamos que, apesar de se tratar de um cargo que prevê ensino médio, a maioria que se autodeclarou preto/a ou pardo/a, de acordo com os critérios do IBGE, possuía graduação em diversas áreas do conhecimento. Merecem destaque os/as candidatos/as com formação em Direito e Engenharia, formados/as pela Universidade de São Paulo (USP), pela Pontifícia Universidade Católica de Campinas (PUC-Campinas), pela Pontifícia Universidade Católica de São Paulo (PUC-SP) e por universidades federais de todas as regiões do país. Além disso, pessoas com pós-graduação stricto sensu em andamento. Desses candidatos, muitos não haviam conseguido inserção no mercado de trabalho em escritórios, de acordo com o nível de conhecimento que possuem, e atuavam de forma autônoma, na maioria das vezes em cidades de pequeno porte.

Ao refletir sobre essa realidade, observamos que, apesar da formação acadêmica excelente, estavam alijados do mercado de trabalho, muito possivelmente em decorrência do preconceito e da discriminação raciais reservados às pessoas negras. As instituições atendem a determinados grupos raciais que fazem valer seus interesses econômicos e políticos, de modo que o racismo que estrutura a sociedade também compõe os espaços de trabalho.

Percebe-se, portanto, que a excelência da formação acadêmica não venceu o preconceito, ao contrário, mostrou sua face institucional e estrutural. Afinal, não se trata de qualificação, a verdade nua e crua é que não são aceitos/as em determinados meios sociais para funções relevantes por sua aparência de pessoas pretas.

O fenótipo torna certos espaços de trabalho inacessíveis, por mais qualificada que a pessoa possa ser. Conforme lembra Almeida (2018), uma forma de discriminação racial que estratifica e afeta a ascensão social, o reconhecimento e o sustento material dos membros do grupo social não branco. Aliás, esse autor adverte que a ausência de pessoas negras em espaços de poder e prestígio denuncia a desigualdade social, com ênfase no racismo. Consideramos que essas análises não podem soar como estranhas ao/à assistente social, que no seu fazer profissional se depara com histórias 


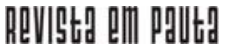

\} AVALIAÇÃO DE FENÓTIPO - SANTOS, T. F. S.; ALARCÓN, M. B. R.; ROCHA, E. F. \}

DOI: $10.12957 /$ REP.2020.51985

de vida que trazem em seu bojo a marca da discriminação racial e da desigualdade. São ilustrativas as palavras de Almeida (2018, p. 41), quando menciona:

Homens brancos não perdem vagas de emprego pelo fato de serem brancos, pessoas brancas não são 'suspeitas' de atos criminosos pela sua condição racial, pessoas brancas não tem sua inteligência ou sua capacidade profissional questionada devido à cor da sua pele.

Também se apresentaram para avaliação de fenótipo pessoas maduras, que estavam desempregadas após anos de trabalho e não conseguiam reinserção no mercado formal em decorrência da idade, apesar de plenamente produtivas. Cabe ressaltar que a ampla oferta de trabalhadores/ as disponíveis para ocupar postos de trabalho ante à reestruturação produtiva faz com que as pessoas com idades acima de 45/50 anos sejam alijadas do mercado formal de trabalho por causa da "idade avançada" ${ }^{2}$. A idade madura funciona como indicativo de alta remuneração (o que nem sempre se traduz como verdade, sobretudo levando-se em conta a questão racial), perfil conservador e dificuldade com as inovações tecnológicas, dentre outros aspectos, apontados pelos detentores dos meios de produção para não contratar pessoas com mais de 45 anos.

Acrescente-se a essa situação o quesito racial, fator que tornará a sobrevivência do indivíduo ainda mais vulnerabilizada. Nesse contexto, o concurso público surge como uma possibilidade de retorno ao mercado de trabalho, dessa vez de forma mais estável e na perspectiva de galgar uma aposentadoria, ainda que proporcional ao tempo de efetivo exercício no serviço público.

Os elementos históricos mostram que a população negra foi deixada à margem das conquistas sociais e compõe, em sua maioria, grupos em alta vulnerabilidade social. O não reconhecimento dessa dívida histórica, que minimizaria o processo de exclusão social, impede que a sociedade avance nas reflexões sobre a realidade que essa população enfrenta, inclusive no acesso a direitos fundamentais e previstos na Constituição Federal, como trabalho, saúde, educação, habitação, entre outros. Se levados em conta fatores como as questões de sexo, por exemplo, a situação tende a se agravar ainda mais em relação às mulheres negras (SOUZA; ROCHA, 2018).

Como assistentes sociais, sabemos que raça, sexo, orientação sexual, origem, dentre outros, também geram processos de opressão, exploração e desigualdade, e esse conhecimento precisa balizar a nossa intervenção. Nesse sentido, a análise das manifestações dos/as candidatos/as à Comissão de Avaliação permitiu ao/à assistente social elaborar essas arti-

\footnotetext{
${ }^{2}$ Disponível em: https://www.valor.com.br/carreira/5220137/o-preconceito-com-os-mais-velhos-esta-aumentando. Acesso em 23 jan. 2019.
} 


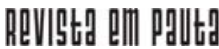

\} AVALIAÇÃO DE FENÓTIPO - SANTOS, T. F. S.; ALARCÓN, M. B. R.; ROCHA, E. F. \}

DOI: $10.12957 /$ REP.2020.51985

culações de como o fenótipo, dentre outros aspectos mencionados, provocam rebatimentos na vida dos sujeitos, com reflexões sócio-históricas que foram socializadas com os demais componentes da Comissão. Assim, concordamos com Motta (2018, p. 74) quando aponta que

As diferenças de idade e de sexo [e de raça]... Assim como outras diferenças sociais, que entrelaçadas com as desigualdades de classe formam um nó difícil de ser desatado nas práticas sociais.

Diante do que foi exposto, a pergunta que fica é: a formação do assistente social não confere elementos para que o/a profissional, diante de um sujeito negro, possa distinguir os indicadores sócio-históricos que impactam a vida daquele indivíduo em razão de sua raça? Isso implica questionar se o/a assistente social pode intervir no combate ao racismo, em diversas frentes, inclusive na avaliação de fenótipo, sabendo que "o racismo é uma marca estruturante da formação sócio-histórica brasileira, e remonta à face bárbara de um país", conforme inferem Koga, Sant'ana e Martinelli (2018, p. 400).

\section{Reflexões finais}

Os elementos trazidos à baila, na atuação na Comissão de Avaliação de Fenótipo, e que dizem do movimento da história na sociedade capitalista e do rebatimento dessa estrutura de racismo, exploração e opressão na concretude da vida dos sujeitos negros, não deveriam soar como estranhos às apreensões que o/a assistente social faz em sua prática no espaço sócio-ocupacional. Tampouco indicam que, para apreender essas dimensões da vida cotidiana do racismo, é necessário ao/à assistente social ser especialista na temática.

Compreendemos que esses elementos compõem a análise da intervenção profissional; portanto, é preciso ampliar a aproximação a eles para qualificar a intervenção, pois o racismo é um elemento estrutural que compõe a organização econômica, social e política da sociedade capitalista, gerando desigualdades e violência. O combate ao racismo exige ações que promovam a inclusão efetiva das pessoas, do modo como o realizado pela Comissão de Avaliação de Fenótipo, na qual o/a assistente social, com base em sua formação teórica, tem condições de compor e contribuir.

Por fim, consideramos que a atuação do/a assistente social na Comissão de Avaliação de Fenótipo possibilitou destacar a dimensão política da nossa profissão, que, em seus componentes éticos e técnicos, busca uma determinada direção societária, de acordo com os princípios que balizam o projeto ético-político da profissão. Ao fazer isso, saímos do nível do aparente e adentramos em processos sócio-históricos, os quais conferem reais contribuições para a participação do/a assistente social nas Comissões de Avaliação. 


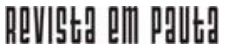

\} AVALIAÇÃO DE FENÓTIPO - SANTOS, T. F. S.; ALARCÓN, M. B. R.; ROCHA, E. F. \}

DOI: $10.12957 /$ REP.2020.51985

\section{Referências}

ALMEIDA, S. O que é racismo estrutural? Belo Horizonte: Letramento, 2018. BOEHEN, C. Negros enfrentam mais dificuldades que bancos no mercado de trabalho, diz MPT. 2017. Disponível em https://agenciabrasil.ebc.com.br/ geral/noticia/2017-11/negros-enfrentam-mais-dificuldades-que-negros-nomercado-de-trabalho-diz-mpt. Acesso em 19 mai 2020.

BRASIL. Diretrizes curriculares. Curso de Serviço Social. Perfil do Bacharel em Serviço Social. 1999. Disponível em: http://www.abepss.org.br/arquivos/ anexos/comissao-de-especialistas-1999-diretrizes-curriculares-formuladapela-201608060344575120480.pdf. Acesso em: 15 out. 2017.

BRASIL. Estatuto da igualdade racial. 2010. Disponível em: http://www. planalto.gov.br/ccivil_03/_ato2007-2010/2010/lei/l12288.htm. Acesso em: 15 out. 2017.

BRASIL. Lei federal n. 12.990, de 9 de junho de 2014. Dispõe sobre a reserva aos negros de $20 \%$ das vagas oferecidas nos concursos públicos para provimento de cargos efetivos e empregos públicos no âmbito da administração pública federal, das autarquias, das fundações públicas, das empresas públicas e das sociedades de economia mista controladas pela União. 2014. Disponível em: http://www.planalto.gov.br/CCIVIL_03/_Ato20112014/2014/Lei/L12990.htm. Acesso em: 15 out.2019.

BRASIL. ADPF 186/Distrito Federal. 2009. Disponível em: http://www. stf.jus.br/arquivo/cms/noticiaNoticiaStfArquivo/anexo/ADPF186.pdf. Acesso em: 15 out. 2017.

BRITO, D. Cotas foram a revolução silenciosa no Brasil, afirma especialista. Disponível em https://agenciabrasil.ebc.com.br/educacao/noticia/2018-05/ cotas-foram-revolucao-silenciosa-no-brasil-afirma-especialista. Acesso em 19 mai 2020.

CFESS. $2^{\circ}$ dia de Encontro debate formação profissional e políticas de ação afirmativa. 2010. Disponível em: http://www.cfess.org.br/visualizar/noticia/ cod/470. Acesso em: 15 out. 2017.

CFESS. Código de ética do/a assistente social. Brasília: CFESS, 2012.

CFESS. Série assistente social no combate ao preconceito: racismo. Caderno 3. Brasília: CFESS, 2016.

CNJ. Primeiro censo do poder judiciário. Disponível em: http://www. cnj.jus.br/pesquisas-judiciarias/censo-do-poder-judiciario. [2014]. Acesso em: 15 out. 2017.

CNJ. Pedido de Providências 0002248-46.2012.2.00.0000.2012. Disponível em: http://www.cnj.jus.br/Infojurisl2/downloadDocumento.seam 


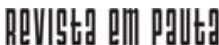

\} AVALIAÇÃO DE FENÓTIPO - SANTOS, T. F. S.; ALARCÓN, M. B. R.; ROCHA, E. F. \}

DOI: $10.12957 / R E P .2020 .51985$

;jsessionid=A45893639B4017CC50750E6C3AFDF928?fileName= 22484620122000000_PP+0002248-46.2012.2.00.0000.pdf\&num Processo $=0002248-46.2012 .2 .00 .0000 \&$ numSessao $=155 \% \mathrm{C} 2$ $\% \mathrm{AA}+\mathrm{Sess} \% \mathrm{C} 3 \% \mathrm{~A} 3 \mathrm{o}+\mathrm{Ordin} \% \mathrm{C} 3 \% \mathrm{~A} 1 \mathrm{ria} \& \mathrm{idJurisprudencia}=$ 45832\&decisao $=$ false. Acesso em: 3 mar. 2018.

CNJ. Resolução n. 203/2015. 2015a. Disponível em: http://www.cnj.jus.br/ files/atos_administrativos/resoluo-n203-23-06-2015-presidncia.pdf. Acesso em: 15 out. 2017.

CNJ. Processo Comissão 0006940-88.2012.2.00.0000. Disponível em: https://www.cnj.jus.br/Infojuris/2/Jurisprudencia.seam;jsessionid= EFA0CA7CBAD971826620B0C2333B497D?jurisprudencialdJuris= 47681 \&indiceListaJurisprudenc $i a=12$ \& firstResult $=3975$ \&tipoPesq uisa=BANCO. 2015b. Acesso em: 3 mar. 2018.

CRUZ, C. F. S.; SANTOS, D. F. C.; SILVA, A. C. O. Serviço Social e a questão racial: trajetória de ausência à efetivação dos direitos da população negra no Brasil. In: SEMINÁRIO MINEIRO DE ASSISTENTES SOCIAIS: 80 ANOS DE SERVIÇO SOCIAL: TENDÊNCIAS E DESAFIOS, 4. 2016. Disponível em: http://cress-mg.org.br/hotsites/Upload/Pics/9a/9aea00f0-7e67-4072-9618bad544c098d7.pdf. Acesso em: 15 out. 2017.

DOUGLAS, W. Cotas, autodeclaração e fraude em concursos. Disponível em: https://williamdouglas.com.br/cotasefraude. 2017. Acesso em: 15 out. 2017.

GOIS, D. A. de. Famílias, desenraizamento social e privações de direitos. Serviço Social e temas sociojurídicos: debates e experiências. Rio de Janeiro: Lumen Juris, 2014.

IAMAMOTO, M. V. A formação acadêmico-profissional do Serviço Social brasileiro. Revista Serviço Social e Sociedade, São Paulo, n. 120, out./dez. 2014. Disponível em: http://www.scielo.br/pdf/sssoc/n120/02.pdf. Acesso em: 15 out. 2017.

KOGA, D.; SANT'ANA, R. S.; MARTINELLI, M. L. Questão étnico-racial: desigualdades, lutas e resistência. Revista Serviço Social e Sociedade, n. 133, São Paulo, 2018. Disponível em: http://www.scielo.br/pdf/sssoc/n133/ 0101-6628-sssoc-133-0399.pdf. Acesso em: 9 jan. 2019.

MARTINELLI, M. L. Reflexões sobre o Serviço Social e o projeto ético-político profissional. Revista Emancipação, Ponta Grossa. v. 6, n. 1, 2006.

MARTINELLI, M. L. A pergunta pela identidade profissional do Serviço Social: uma matriz de análise. Revista Serviço Social e Saúde, Campinas, v. 12, n. 2, jul./dez. 2013. Disponível em: https://periodicos.sbu.unicamp.br/ojs/ index.php/sss/article/view/8639491. Acesso em: 23 out. 2019. 


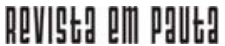

\} AVALIAÇÃO DE FENÓTIPO - SANTOS, T. F. S.; ALARCÓN, M. B. R.; ROCHA, E. F. \}

DOI: $10.12957 /$ REP.2020.51985

MESQUITA, M. $2^{\circ}$ dia de Encontro debate formação profissional e políticas de ação afirmativa. 2010. Disponível em: http://www.cfess.org.br/visualizar/ noticia/cod/470. Acesso em: 23 out. 2019.

MORAES, J.; MARTINELLI, M. L. A importância da categoria mediação para o Serviço Social. In: Seminário Latinoamericano de Escuela de Trabajo Social, 20, 2012. Disponível em: http://www.cressrn.org.br/files/arquivos/ Y6O09Vi7X17oOE584R0e.pdf. Acesso em: 15 out. 2017.

MOTTA, D. Do universal ao específico: entrelaçando gênero, raça e classe. Cadernos Cemarx, n. 11, 2018 Disponível em: https://www.ifch.unicamp.br/ ojs/index.php/cemarx/article/viewFile/3366/2554. Acesso em: 25 jan. 2019. PAIVA, B.; SALES, M. A nova ética profissional: práxis e princípios. In: BONETTI, D. A. et al. Serviço Social e ética: convite a uma nova práxis. São Paulo: Cortez, 2012.

SANTOS, F. D.; DOUGLAS, W. Cotas e combate à corrupção. 2016. Disponível em: http://noblat.oglobo.globo.com/geral/noticia/2016/08/cotas-ecombate-corrupcao.html. Acesso em: 25 jan. 2019.

SOUZA, J. M. A. de. A categoria de totalidade e o Serviço Social: subsídios teóricos para uma a aproximação ao processo de implementação das diretrizes curriculares. 2009. Dissertação (Mestrado em Serviço Social) UFPE, Centro de Ciências Sociais Aplicadas, Pós-Graduação em Serviço Social, Recife, 2009.

SOUZA, A. P. H.; ROCHA, E. F. Destituição do poder familiar, racismo e justiça: uma reflexão interdisciplinar necessária. In: BORGIANNI, E.; MACEDO, L. M. O Serviço Social e a psicologia no universo judiciário. Campinas: Papel Social, 2018.

TJSP. Resolução n. 719/2015. 2015. Disponível em: http://dje.tj.sp.gov.br/ cdje/consultaSimples.do?cdVolume $=10 \&$ nuDiario $=2011 \&$ cdCaderno $=$ 10\&nuSeqpagina=2. Acesso em: 25 out. 2017.

DOI: $10.12957 /$ rep.2020.51985

Recebido em 21 de julho de 2019.

Aprovado para publicação em 05 de fevereiro de 2020.

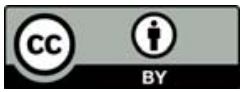

A Revista Em Pauta: Teoria Social e Realidade Contemporânea está licenciada com uma Licença Creative Commons Atribuição 4.0 Internacional. 